\title{
DESEMPENHO DE CONCRETOS PREPARADOS COM CIMENTOS PORTLAND CP IV E CP V UTILIZANDO O MÉTODO DE DOSAGEM IPT/EPUSP: UM ESTUDO DE CASO
}

\author{
Marcelo Tramontin Souza ${ }^{1,2 *}$, Ricardo Junckes ${ }^{3}$, Tiago Bender Wermuth ${ }^{4}$, Sabrina Arcaro ${ }^{5}$, \\ Fabiano Raupp Pereira ${ }^{5}$, Antonio Pedro Novaes de Oliveira ${ }^{2}$
}

\begin{abstract}
${ }^{1}$ Programa de Pós-Graduação em Ciência, Inovação e Modelagem em Materiais (PROCIMM), Laboratório de Ensaios Mecânicos e Resistência dos Materiais (LEMER), Universidade Estadual de Santa Cruz (UESC). Campus Sonae Nazaré de Andrade, Rod. Jorge Amado, Km 16 - Salobrinho, 45662-900, Ilhéus, BA.

${ }^{2}$ Programa de Pós-Graduação em Ciência e Engenharia de Materiais (PGMAT), Laboratório de Materiais Vitrocerâmicos (VITROCER), Universidade Federal de Santa Catarina (UFSC). Campus Universitário - Trindade, 88040-900, Florianópolis, SC.

${ }^{3}$ Programa de Pós-Graduação em Engenharia Civil (PPGEC, Laboratório de Materiais de Construção Civil (LMCC), Departamento de Engenharia Civil (ECV). Campus Universitário - Córrego Grande, 88037-000, Florianópolis, SC.

${ }^{4}$ Programa de Pós-Graduação em Engenharia de Minas, Metalúrgica e de Materiais (PPGE3M), Laboratório de Materiais Cerâmicos (LACER), Departamento de Materiais, Universidade Federal do Rio Grande do Sul - UFRGS, Osvaldo Aranha 99, 90035190, Porto Alegre, RS.

${ }^{5}$ Programa de Pós-Graduação em Ciência e Engenharia de Materiais (PPGCEM), Laboratório de Cerâmica Técnica (CerTec), Universidade do Extremo Sul Catarinense (UNESC), Av. Universitária 1105, P.O. Box 3167, Criciúma, SC.
\end{abstract}

*E-mail: engmarcelosouza@hotmail.com

\section{RESUMO}

O desempenho de concretos é fortemente afetado pelas condições de preparação e pelos materiais constituintes. Uma combinação inadequada dos parâmetros de processo e dos materiais utilizados pode afetar o desempenho dos concretos preparados. As variáveis composicionais incluem o tipo de cimento Portland e adições (como escórias e pozolanas), bem como as proporções dos demais constituintes, tais como agregados graúdos e miúdos e a relação água/cimento. Nesse sentido, os métodos de dosagem surgem como ferramentas para orientar os trabalhadores na obtenção de concretos com melhores desempenhos físico-mecânicos. Dentre os principais métodos brasileiros de dosagem, o método IPT/EPUSP tem sido amplamente aceito, pois é versátil e simples. Desta forma, este trabalho busca avaliar a influência de dois tipos de cimento - Portland, CP IV (pozolânico) e CP V ARI (alta resistência inicial) - nas propriedades mecânicas de concretos dosados de acordo com o método IPT/EPUSP. Os resultados revelam que os diagramas de dosagem obtidos permitem correlacionar, de forma sucinta e eficaz, os parâmetros de dosagem com as propriedades mecânicas desejadas para uma finalidade específica.

Palavras-chave: Concreto. Método de dosagem. Resistência à compressão.

\section{Introdução}

O concreto é um material resultante da mistura íntima e equilibrada de um ligante (cimento Portland), agregados miúdos, agregados graúdos e água. A obtenção de bons desempenhos, conforme requisitos técnicos para concretos, dependerá tanto dos materiais constituintes como das proporções entre eles. Assim, para um melhor aproveitamento das características intrínsecas de cada material constituinte, é necessário o conhecimento aprofundado dos materiais que constituem o concreto e a influência destes nas suas propriedades. Além disso, entende-se que - para se ter uma combinação adequada e econômica dos constituintes - os métodos de dosagem de concreto surgem como alternativa interessante a ser empregada.

Os métodos de dosagem surgem, portanto, como ferramentas básicas imprescindíveis para alcançar melhores desempenhos físico-mecânicos, possibilitando, assim, níveis 
superiores de qualidade, com custos significativamente menores. $\mathrm{O}$ objetivo do proporcionamento do concreto está relacionado à escolha dos materiais adequados entre aqueles disponíveis e a combinação mais econômica que resulte em um concreto com características de desempenho mínimo pré-estabelecido[1]. Atualmente, existem diferentes métodos brasileiros de dosagem tais como: ABCP, IPT/EPUSP, ITERS, INT, SCNF[2,3]. Normalmente, estes métodos se baseiam na determinação de um traço inicial, a partir do qual são feitos ajustes experimentais para manipular, de forma controlada, as propriedades de interesse em função dos materiais utilizados. Isso resultou em melhores desempenhos físico-mecânicos e maior durabilidade com superiores níveis de qualidade.

Aliado aos métodos de dosagem, uma das principais causas da variação das características e propriedades do concreto é o tipo de cimento Portland empregado devido às variações de composição, uma vez que podem apresentar adições de escórias e pozolanas. A composição do cimento Portland influencia o tempo de cura e as propriedades finais do concreto [4]. Portanto, para um melhor aproveitamento das características e propriedades de um concreto, faz-se necessário um conhecimento mais detalhado e específico sobre os materiais que o compõem.

De acordo com a Associação Brasileira de Cimento Portland [5], existem, no mercado, diversos tipos de cimento Portland. Os principais e mais empregados no setor da construção civil são: cimento Portland comum (CP I e CP I-S); cimento Portland composto (CP - II); cimento Portland de alto-forno (CP - III); cimento Portland pozolânico (CP - IV) e cimento Portland de alta resistência inicial (CP V ARI e CP V ARI RS) [6]. A variação composicional de cada tipo de cimento Portland tem influência direta sobre as suas características e propriedades, o que permite atender às exigências demandadas conforme o local de sua aplicação.

Neste contexto, este trabalho busca avaliar a influência dos cimentos Portland CP IV (pozolânico) e CP V ARI (alta resistência inicial) nas propriedades de concretos dosados com base nos procedimentos descritos no método IPT/EPUSP [7]. A definição dos dois tipos de cimento Portland selecionados para este trabalho teve como base a variação composicional entre ambos já que, desta maneira, um maior contraste entre os resultados é esperado com o método de dosagem aplicado. $\mathrm{O}$ primeiro cimento Portland (CP IV), amplamente utilizado em ambientes mais agressivos (ácidos e sulfatos), apresenta, normalmente, um teor elevado de material pozolânico (15$50 \% \mathrm{~m}$ ), que tende a melhorar a resistência a cloretos e sulfatos, enquanto o segundo ( $\mathrm{CP} \mathrm{V}$ ARI), que não contém material pozolânico, apresenta maior reatividade, sendo indicado para todos os tipos de obras [6].

\section{Materiais e métodos}

Para produção dos concretos, foram utilizados: cimentos Portland (Votoran) CP IV (pozolânico) e CP V ARI (alta resistência inicial), agregados miúdos (areia de quartzo e areia de britagem), agregados graúdos (basalto) e um aditivo plastificante (Tec-Flow 510) tipo P (policarboxilato).

A distribuição de tamanho de partículas e o módulo de finura dos agregados (natural e industrial) foram determinados por meio de peneiras circulares laboratoriais, conforme ABNT NBR 7217 [8], com o objetivo de determinar a distribuição de tamanho de partículas ideal (maior fluidez e empacotamento) para a mistura de ambos os agregados. A norma estabelece as zonas (limites) ótimas e utilizáveis para a distribuição de tamanho de partículas dos agregados miúdos em contraste com o módulo de finura, com valores entre 2,20 e 2,90 para a zona ótima e, entre 1,5 e 3,5, para a zona utilizável.

Subsequentemente, foram determinados os traços dos concretos calculados e os ajustes necessários para obtenção da consistência do abatimento por tronco de cone em $12 \pm 5 \mathrm{~mm}$ de acordo com a norma ABNT NBR NM 67 [9]. A Tabela 1 mostra os traços obtidos (já ajustados pelo ensaio de abatimento), com valores da razão mássica de agregado seco/cimento $(\mathrm{m})$ fixados em 3,5; 5,0 e 6,5 para os concretos com os dois tipos de cimentos Portland. Os traços diferem apenas na razão água/cimento (indicado na Tabela 1). As quantidades de cimento Portland e agregados são as mesmas. Os traços foram estabelecidos com avaliação prévia do teor de argamassa ideal $(\alpha)$, e a razão de água e materiais secos $(\mathrm{H})$ pela análise visual das características de argamassas preparadas com agregados miúdos naturais e adotadas como referência para preparação dos concretos $(\alpha=53 \%$ e $\mathrm{H}=9 \%)$.

Tabela 1: Traços ajustados para os concretos.

\begin{tabular}{|c|c|c|c|c|c|c|c|}
\hline \multirow{2}{*}{$\mathbf{m}$} & \multirow{2}{*}{$\mathbf{C}$} & \multicolumn{2}{|c|}{$\begin{array}{c}\text { Agregado } \\
\text { miúdo(areia) }\end{array}$} & \multirow{2}{*}{$\begin{array}{c}\text { Agregado } \\
\text { graúdo } \\
\text { (brita) }\end{array}$} & \multirow{2}{*}{$\begin{array}{c}\text { Adit. } \\
(\%)\end{array}$} & \multirow{2}{*}{$\begin{array}{l}\text { a/c } \\
\text { CP IV }\end{array}$} & \multirow{2}{*}{$\begin{array}{l}\mathrm{a} / \mathrm{c} \\
\mathrm{CPV}\end{array}$} \\
\hline & & $\underset{l}{\text { Industria }}$ & Natural & & & & \\
\hline $\begin{array}{l}3, \\
5\end{array}$ & 1 & 0,76 & 0,62 & 2,12 & 0,80 & 0,31 & 0,34 \\
\hline $\begin{array}{l}5, \\
0\end{array}$ & 1 & 1,20 & 0,98 & 2,82 & 0,80 & 0,42 & 0,42 \\
\hline $\begin{array}{l}6, \\
5\end{array}$ & 1 & 1,64 & 1,34 & 3,52 & 0,80 & 0,48 & 0,49 \\
\hline
\end{tabular}

Onde: $\mathrm{m}=$ traço, $\mathrm{C}=$ cimento e $\mathrm{a} / \mathrm{c}=$ razão água/cimento.

Foram produzidos dois tipos de concreto: o primeiro dosado com o cimento Portland CP IV (pozolânico); o segundo, com cimento Portland CP V ARI (alta resistência inicial). Os demais constituintes foram os mesmos para ambos os concretos e o volume preparado para cada traço foi de 20 litros. 
A proporção mássica dos constituintes dos concretos referente a este volume foi determinada por meio das massas específicas dos agregados (miúdo e graúdo) e de cada um dos cimentos Portland. Foi necessária ainda a determinação da umidade dos agregados já que ela é importante para a correção do traço utilizado, evitando-se assim alterações na razão água/cimento e trabalhabilidade do concreto no estado fresco.

A massa específica $(\rho)$ dos agregados miúdos e dos dois tipos de cimento Portland foi calculada com base na Equação 1 e utilizando-se de um picnômetro constituído por um balão de Erlenmeyer [10]

$$
\rho=\frac{m_{s}}{P_{a g}-\left(P_{a g+s}-m_{s}\right)} \rho=\frac{m_{s}}{P_{a g}-\left(P_{a g+s}-m_{s}\right)}
$$

Em que: $m_{s}=$ massa $(\mathrm{kg})$ da amostra seca, $P_{a g}=$ massa $(\mathrm{kg})$ do balão de Erlenmeyer cheio de água (temperatura ambiente, $\left.20^{\circ} \mathrm{C}\right)(\mathrm{kg})$, $P_{a g+s}=$ massa do balão de Erlenmeyer cheio de água com a amostra seca $(\mathrm{kg})$.

A massa específica $(\rho)$ do agregado graúdo foi obtida pelo método da proveta [11], que consiste no preenchimento parcial de uma proveta graduada com água e a inserção da amostra do agregado. A massa específica foi obtida conforme a Equação 2.

$$
\rho=\frac{m_{a s}}{v_{2}-v_{1}} \rho=\frac{m_{a s}}{v_{2}-v_{1}}
$$

Em que: $m_{a s}=$ massa da amostra seca $(\mathrm{kg}), v_{2}=$ volume de água na proveta com a amostra seca $\left(\mathrm{m}^{3}\right)$ e $v_{l}=$ volume de água na proveta sem a amostra $\left(\mathrm{m}^{3}\right)$;

O teor de umidade. $U(\%)$ dos agregados foi obtido a partir da Equação 3.

$$
U=\frac{m_{u}-m_{s}}{m_{u}} \times 100 U=\frac{m_{u}-m_{s}}{m_{u}} \times 100
$$

Em que: $m_{u}=$ massa da amostra úmida $(\mathrm{kg})$ e $m_{s}=$ massa da amostra seca $(\mathrm{kg})$.

O consumo de cimento Portland nos concretos foi calculado a partir dos traços obtidos e da massa específica aparente dos concretos. Para determinação da massa específica aparente do concreto, utilizaram-se um recipiente metálico com volume conhecido (dimensões de 15 x 15 x $15 \mathrm{~cm}$ ) e uma balança digital (KATASHI). O resultado foi calculado a partir da Equação 4. $\rho=\frac{m_{s}}{v} \rho=\frac{m_{s}}{v}$

Em que: $m_{s}=$ massa da amostra seca $(\mathrm{kg})$ e $v=$ volume da amostra $\left(\mathrm{m}^{3}\right)$.

Para cada traço de concreto produzido e tipo de cimento Portland, foram confeccionados seis corpos de prova cilíndricos com dimensões de 10 × $20 \mathrm{~cm}$, para ensaios de resistência à compressão. Após três dias, os corpos de prova foram desmoldados e curados em câmara úmida, conforme norma ABNT NBR 5738[12].

Nas idades estabelecidas de 3, 7 e 28 dias, os corpos de prova foram retificados e, em uma etapa posterior, submetidos a ensaios de compressão em uma prensa hidráulica (Shimadzu UH 2000KNA), conforme procedimentos da norma ABNT NBR $5739[13]$.

\section{Resultados e discussão}

A Tabela 2 apresenta a composição química e características dos cimentos Portland CP IV e CP V. A presença de $\mathrm{SiO}_{2}(29,8 \% \mathrm{~m})$ em teores significativos no cimento Portland CP IV está relacionada às adições pozolânicas, que oferecem maior resistência química e durabilidade, sendo, portanto, indicado para ambientes mais agressivos (com forte presença de sulfatos).

Tabela 2: Composição química e características dos cimentos Portland.

\begin{tabular}{ccc}
\hline $\begin{array}{c}\text { Composição química dos óxidos } \\
\text { constituintes } \begin{array}{c}\text { C massa) } \\
\text { propriedades físicas }\end{array}\end{array}$ & IV & V \\
\cline { 2 - 3 } & 39,5 & 65,6 \\
\hline $\mathrm{CaO}$ & 29,8 & 15,0 \\
\hline $\mathrm{SiO}_{2}$ & 11,5 & 3,3 \\
\hline $\mathrm{Al}_{2} \mathrm{O}_{3}$ & 4,1 & 4,6 \\
\hline $\mathrm{MgO}$ & 3,8 & 3,4 \\
\hline $\mathrm{Fe}_{2} \mathrm{O}_{3}$ & 3,6 & 2,7 \\
\hline $\mathrm{SO}_{3}$ & 1,5 & 0,9 \\
\hline $\mathrm{K}_{2} \mathrm{O}$ & 0,6 & 0,4 \\
\hline $\mathrm{TiO}_{2}$ & 0,5 & 0,2 \\
\hline $\mathrm{Na}_{2} \mathrm{O}$ & 4,9 & 3,7 \\
\hline $\mathrm{Perda}_{\mathrm{ao}}$ fogo & 2,7 & 3,0 \\
\hline $\mathrm{D}_{10}(\mu \mathrm{m})$ & 12,6 & 12,7 \\
\hline $\mathrm{D}_{50}(\mu \mathrm{m})$ & 37,9 & 30,0 \\
\hline $\mathrm{D}_{90}(\mu \mathrm{m})$ & 12,2 & 6,4 \\
\hline Área de superfície específica $\left(\mathrm{m}^{2} / \mathrm{g}\right)$ & &
\end{tabular}


A presença de pozolanas no cimento Portland CP IV diminui a sua reatividade e- por isso- sua hidratação é mais lenta. Já o cimento Portland $\mathrm{CP} \mathrm{V}$, com maior concentração de $\mathrm{CaO}$ $(65,6 \%)$, apresenta elevada reatividade e alta resistência já nas primeiras idades.

A Figura 1 mostra a distribuição granulométrica dos agregados miúdos (areias de britagem e natural) e os limites ótimos de utilização, corroborando com o módulo de finura dos mesmos materiais, mostrados na Tabela 3 . Observa-se que a distribuição granulométrica da areia natural (com módulo de finura de 1,14) ficou fora do limite inferior da zona utilizável $(3,50$ a 1,55). Desta forma, a distribuição granulométrica da areia de britagem (com módulo de finura de 3,03) ficou próxima do limite superior da zona utilizável. Desta forma, optou-se pela utilização de uma mistura de $65 \%$ de areia de britagem e $35 \%$ de areia natural, cuja distribuição granulométrica ficou- majoritariamentedentro da zona ótima, conforme mostrado na Figura 1. Nesta adequação, foi excluída apenas a peneira com abertura de $0,3 \mathrm{~mm}$, porém ainda dentro dos limites utilizáveis. O módulo de finura apresentado pela mistura foi de 2,37 e para o agregado graúdo, de 2,45 .

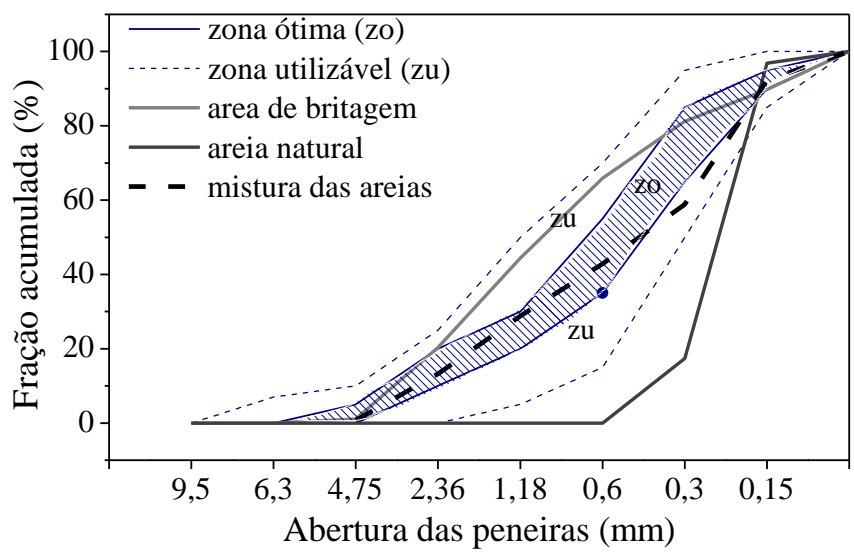

Figura 1: Limites de distribuição de tamanho de partículas do agregado miúdo (areia), segundo ABNT NBR 7211 [14], e distribuição de tamanho de partícula para as areias de britagem, natural e mistura (65\% de areia de britagem e $45 \%$ de areia natural).

Tabela 3: Módulo de finura das zonas ótima e utilizável e dos agregados utilizados.

Módulo de finura

\begin{tabular}{cc}
\hline Zona ótima & 2,90 a 2,20 \\
\hline Zona utilizável & 3,50 a 1,55 \\
\hline Areia de britagem & 3,03 \\
\hline Areia natural & 1,14 \\
\hline Mistura das areias & 2,37 \\
\hline Agregado graúdo (areia) & 2,45 \\
\hline
\end{tabular}

As massas específicas das areias ficaram em $2.645 \mathrm{~kg} / \mathrm{m}^{3}$ e $2.655 \mathrm{~kg} / \mathrm{m}^{3}$ para a areia natural e areia de britagem, respectivamente. A massa específica do agregado graúdo (basalto), ficou em $3.040 \mathrm{~kg} / \mathrm{m}^{3}$. As massas específicas dos cimentos ficaram em $2.800 \mathrm{~kg} / \mathrm{m}^{3}$ para o cimento Portland CP IV e $3.100 \mathrm{~kg} / \mathrm{m}^{3}$ para o cimento Portland CP V. As diferenças entre as massas específicas dos cimentos Portland analisados estão relacionadas com as características intrínsecas de suas composições, já que o cimento Portland CP IV possui pozolanas, cuja massa específica é menor que a do clínquer puro (principal componente do cimento Portland). A Figura 2 mostra a variação da massa específica $(\rho)$ dos concretos em função da razão agregados secos/cimento $(\mathrm{m})$.

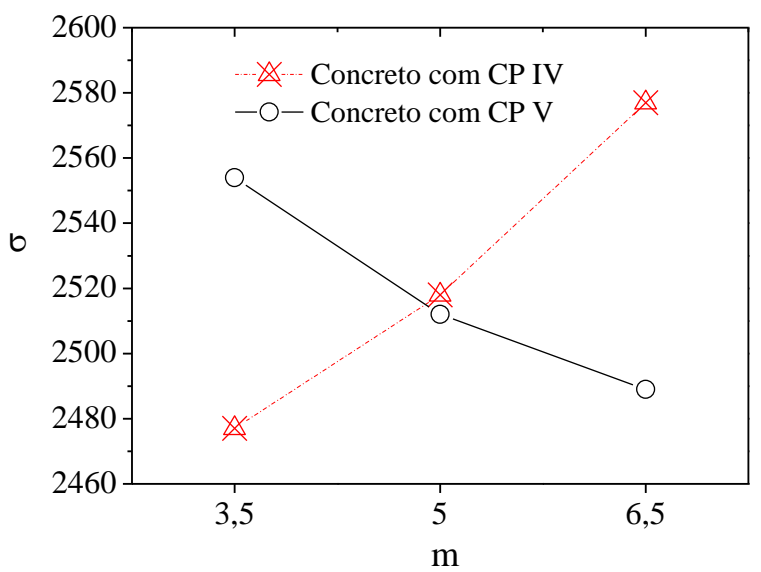

Figura 2: Massa específica $(\rho)$ dos concretos produzidos em função da razão agregados secos/cimento $(\mathrm{m})$.

Observa-se, a partir da análise da Figura 2 que, para o cimento Portland CP IV, quanto menor a razão agregados secos/cimento, menor é a massa específica. Entretanto, para o cimento Portland $\mathrm{CP} \mathrm{V}$, quanto menor a razão agregados secos/cimento, maior é a massa específica do concreto. Esse comportamento está relacionado com a alteração do teor de cimento Portland e agregado graúdo (brita) no concreto preparado. De fato, o cimento Portland CP IV possui massa específica menor $\left(2.800 \mathrm{~kg} / \mathrm{m}^{3}\right)$ em relação ao agregado basalto $\left(3.050 \mathrm{~kg} / \mathrm{m}^{3}\right)$, enquanto o cimento Portland $\mathrm{CP} \mathrm{V}$ possui massa específica maior $\left(3.100 \mathrm{~kg} / \mathrm{m}^{3}\right)$ em relação ao mesmo agregado. Assim, um menor teor de cimento Portland tende a diminuir a massa específica para o concreto com CP V e aumentar para o concreto com CP IV.

Dessa forma, fica evidente, que a massa específica de um concreto é proporcional à massa específica de seus constituintes. Um concreto típico possui massa específica em torno de 2.400 $\mathrm{kg} / \mathrm{m}^{3}[14]$. Todavia, os concretos produzidos neste trabalho apresentaram valores de massa específica superiores a 2.500 $\mathrm{kg} / \mathrm{m}^{3}$, atingindo valores máximos de $2.578 \mathrm{~kg} / \mathrm{m}^{3}$, o que pode ser justificado pelo uso de basalto como agregado graúdo. Dentre as 
rochas comumente utilizadas como agregados em concretos convencionais, o basalto está entre as mais densas[15].

A Figura 3 mostra a relação água/cimento em função da razão de agregados secos/cimento para os concretos produzidos com os cimentos Portland CP IV e CP V, com e sem aditivo. Sabese que a adição de água diminui a resistência mecânica à compressão dos concretos, e, portanto, é comum utilizar aditivos no concreto para diminuir a quantidade de água necessária e manter a sua trabalhabilidade. Nota-se, na Figura 3, que a utilização do aditivo diminuiu a quantidade necessária de água para os concretos com a mesma consistência. Percebe-se ainda, que à medida que se aumenta a quantidade de agregados, há maior demanda de água. Isto ocorre em consequência de modificações relacionadas às características morfológicas da carga sólida (granulometria e área de superfície específica) no meio líquido, o que ocasiona um aumento do atrito exercido pelo contato entre os corpos sólidos presentes no sistema.

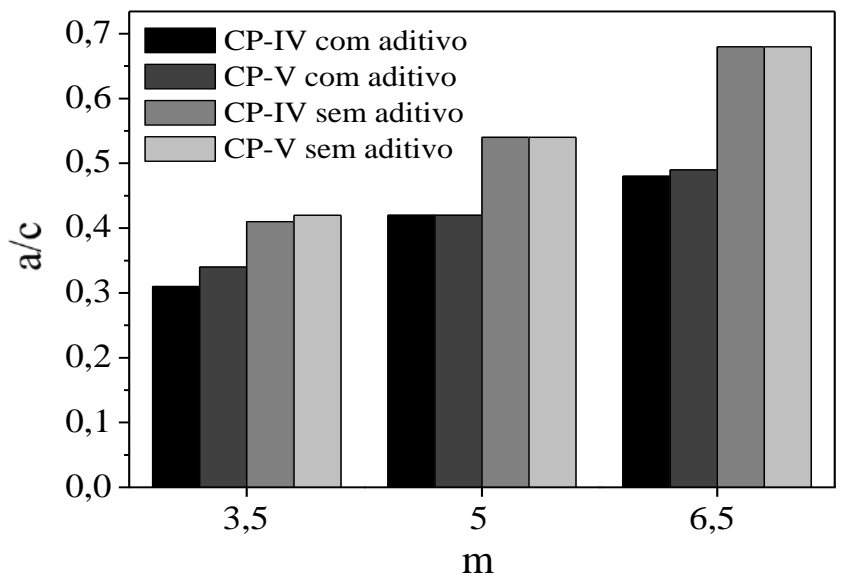

Figura 3: Razão água/cimento (a/c) em função da razão agregados secos/cimento (m) para os concretos com cimento Portland CP IV e CP V, sem e com 0,8\% de aditivo, com consistência fixa de $12 \pm 5 \mathrm{~mm}$.

Na sequência, a resistência à compressão dos concretos foi avaliada para diferentes traços com relação mássica (cimento Portland:agregados) de 1:3,5; 1:5,0 e 1:6,5, conforme a Figura 4. Observa-se que os concretos com cimento Portland CP V apresentam maior resistência mecânica nas primeiras idades devido às características composicionais deste tipo de cimento Portland, que contém uma maior quantidade de $\mathrm{C}_{3} \mathrm{~S}$ (silicato tricálcico). Esta condição reflete-se, consequentemente, no tempo de reatividade destes concretos no processo de hidratação e ganho de resistência nas primeiras idades [16-17].

Os concretos com cimentos Portland pozolânicos (CP IV) apresentaram menores resistências iniciais, pois o efeito da carga pozolânica (cinzas volantes, com alto teor de $\mathrm{SiO}_{2}$ reativa) exerce influência sobre a velocidade de reação com o hidróxido de cálcio $\left(\mathrm{Ca}(\mathrm{OH})_{2}\right.$; Portlandita) produzido durante o processo de hidratação e formação dos compostos de silicatos de cálcio hidratados (C-S-H) com menor velocidade de hidratação global na mistura. Nota-se, com estas características relacionadas ao tipo de cimento Portland, que os concretos com cimento Portland CP IV requereram aproximadamente 7 dias para adquirirem a resistência mecânica dos concretos com cimento Portland CP V obtida com apenas 3 dias de cura. Esta diferença fica ainda mais evidente para as maiores idades, onde aqueles concretos com cimento Portland CP IV requereram aproximadamente de 28 dias para adquirirem a resistência à compressão obtida por volta dos 7 dias pelo cimento Portland CP V.

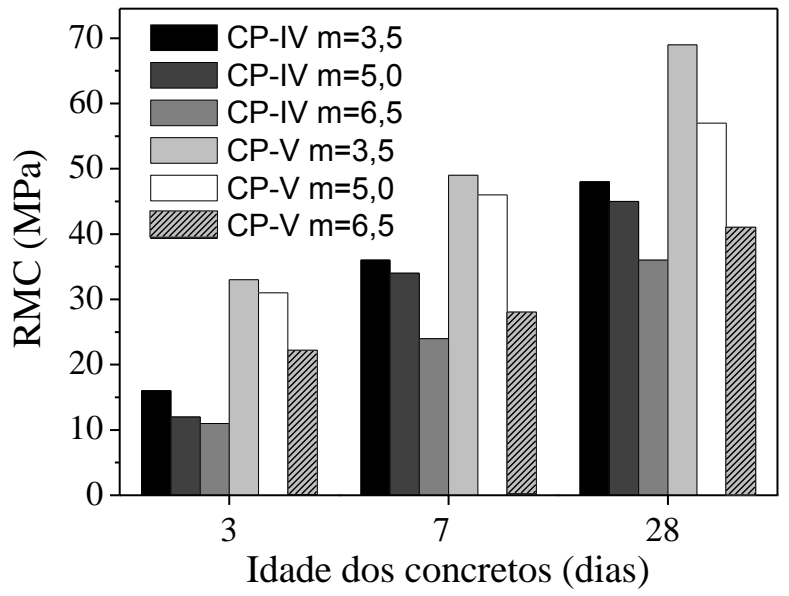

Figura 4: Resistência à compressão dos concretos (RMC) dos cimentos Portland CP IV e CP V com diferentes relações de agregados secos/cimento (m) em função da idade dos concretos.

As Figuras 5 e 6 mostram diagramas de dosagem para os concretos com cimentos Portland CP IV e CP V, respectivamente. Por meio dos diagramas de dosagem, é possível fazer relações, com base na resistência à compressão requerida, entre os fatores a/c, m e C. Em uma especificação hipotética de dosagem cuja resistência à compressão seja de $45 \mathrm{MPa}$ aos 28 dias de idade, os concretos produzidos com cimento Portland CP IV teriam um consumo de cimento de $390 \mathrm{~kg} / \mathrm{m}^{3}$, já os produzidos com cimento Portland CP V teriam um consumo de cimento Portland de 330 $\mathrm{kg} / \mathrm{m}^{3}$.

Outras relações também podem ser obtidas fixando os valores de consumo de cimento Portland, ou razão água/cimento, obtendo-se- assim- os valores de resistência à compressão. Por exemplo, concretos para fins estruturais, segundo a norma ABNT NBR 8953[18], devem apresentar resistência à compressão mínima de $20 \mathrm{MPa}$. Pelos diagramas de dosagem (Figuras 5 e 6), nota-se que, para o concreto com cimento Portland $\mathrm{CP} \mathrm{V}$, essa 
condição é facilmente alcançada com apenas 3 dias de cura para todas as relações de água/cimento apresentadas. Já para o concreto com cimento Portland CP IV, a resistência mínima requerida pela norma não é atingida na mesma idade (3 dias), independentemente da razão água/cimento utilizada.

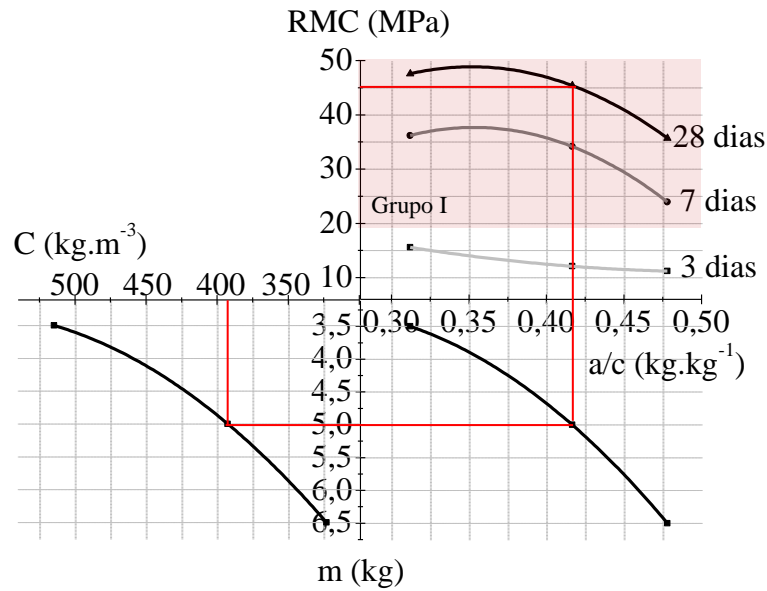

Figura 5: Diagrama de dosagem para o concreto com cimento Portland CP IV.

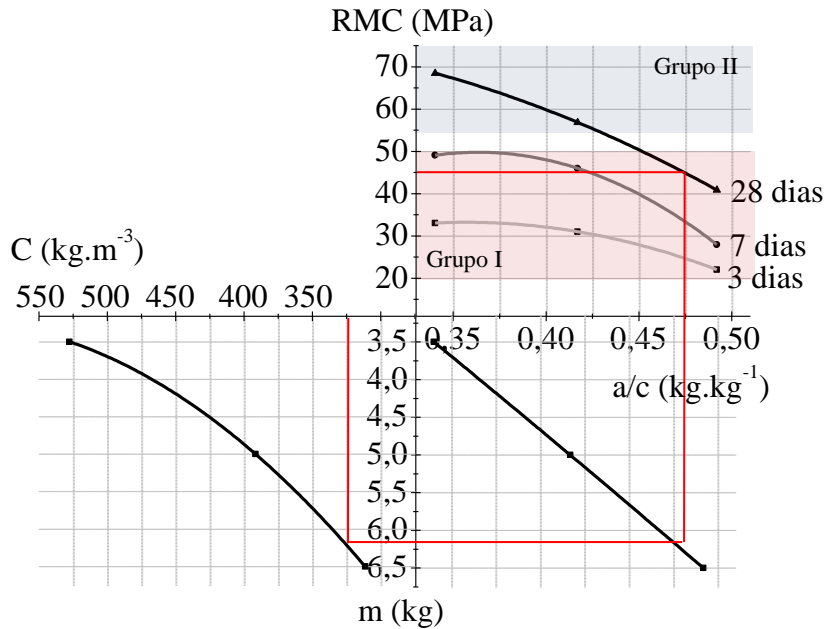

Figura 6: Diagrama de dosagem para o concreto com cimento Portland CP V.

Os concretos para fins estruturais são classificados nos grupos I e II. O primeiro grupo com resistências à compressão variando de 20 a $50 \mathrm{MPa}$ (para obras de modo geral); o segundo, de 55 a $100 \mathrm{MPa}$ (amplamente usados em estruturas de edifícios, pontes e pré-moldados). Considerando essas informações e os diagramas de dosagens, observa-se que apenas o concreto com cimento Portland CP V alcança a resistência mínima compatível com o grupo II para relações de água/cimento menores que 0,42 .
A obtenção de altas resistências à compressão em baixas idades como, por exemplo, para a aplicação de proteção em peças pré-moldadas, remete ao uso de um cimento Portland CP V, desde que o elevado calor de hidratação não prejudique outras propriedades. Já o cimento Portland CP IV pode ser indicado para o uso em peças de concreto com grande volume onde o calor de hidratação elevado, tal como no cimento $\mathrm{CP} \mathrm{V}$, pode comprometer a estrutura construída. Aspectos relacionados à durabilidade também justificam fortemente a utilização do cimento Portland CP IV. Portanto, o conhecimento das condições de aplicação é fundamental para definição dos materiais que serão empregados.

\section{Conclusões}

Os diagramas de dosagem constituem uma ferramenta muito útil para cálculos estruturais, uma vez que fornecem as condições de dosagem para obtenção da resistência desejada e uma estimativa do consumo dos materiais. Na sequência, estão resumidas as principais observações relacionadas às características e ao desempenho dos concretos produzidos a partir do método de dosagem IPT/EPUSP:

- O consumo de cimento Portland por metro cúbico de concreto produzido, fixadas as relações de traço, se manteve praticamente constante para os dois tipos de cimento Portland (CP IV e CP V) estudados.

- A massa específica no estado fresco dos concretos produzidos foi diretamente afetada pelo tipo e quantidade de cimento Portland utilizado, onde se observou aumentos para os concretos com cimento Portland CP V e diminuição para concretos com cimento Portland CP IV.

- A utilização do cimento Portland CP V se mostrou eficiente para a antecipação da resistência à compressão para todos os traços testados.

- Para optimização da dosagem de componentes de concretos, a escolha do tipo de cimento Portland deve refletir a análise de diversos fatores relacionados a aplicação.

- O método utilizado- IPT/EPUSP-permite, de forma clara e eficaz, relacionar os parâmetros de dosagem, tal como o consumo de cimento Portland, razão de agregados secos/cimento e razão água/cimento e a partir desses, estimar a resistência à compressão dos concretos a serem preparados. 


\section{Agradecimentos}

Os autores agradecem à Coordenação de Aperfeiçoamento de Pessoal de Nível Superior (CAPES) e ao Conselho Nacional de Desenvolvimento Científico e Tecnológico (CNPq).

\section{PERFORMANCE OF CONCRETE PREPARED WITH CP IV AND CP V PORTLAND CEMENTS USING THE IPT/EPUSP DOSAGE METHOD: A CASE STUDY}

\begin{abstract}
:
The performance of concretes is strongly affected by the preparation methodology and by the constituent materials, so that an inadequate combination of processing parameters and materials can affect the performance of the concretes. The compositional variables include the type of cement and additions (such as slags and pozzolans), as well as the proportion of other constituents, such as coarse and fine aggregates, and the water/cement ratio. In this sense, mix design methodologies appear as tools to guide laborers in obtaining concretes with better physical-mechanical performance. Among the main Brazilian mix design methodologies, the IPT/EPUSP method has been well-accepted due to its versatility and simplicity. Thus, this work seeks to evaluate the influence of two types of Portland cement, CP IV (pozzolanic) and CP V ARI (high initial strength), on the mechanical properties of concrete dosed according to the IPT/EPUSP method. The results reveal that the obtained mix design diagrams allow correlating, succinctly, and effectively, the proportion of the materials with the desired mechanical properties for a specific application.
\end{abstract}

Keywords: Concrete. Mix design method. Compressive strength.

\section{Referências}

[1] P.K. Mehta, P.J.M. Monteiro, CONCRETE Microstructure, Properties and Materials, 2001.

[2] B.F. Tutikian, P. Helene, Dosagem dos Concretos de Cimento Portland, Concreto Ciência e Tecnol. (2011).

P.R.L. Helene, P.P.P.-S.P. Terzian, Manual de dosagem e controle do concreto, (1993).

[4] D.R. Askeland, Ciência e Engenharia dos Materiais, 2007. https://doi.org/10.1063/1.2729587.

[5] Associação Brasileira de Cimento Portland (ABCP), A VERSATILIDADE DO CIMENTO BRASILEIRO, (n.d.). https://abcp.org.br/cimento/tipos/?politica=sim (accessed July 17, 2020).

[6] Associação Brasileira de Normas Técnicas, ABNT NBR 16697: Cimento Portland - Requisitos, ABNT. (2011). https://doi.org/01.080.10; 13.220.99.

[7] C.E.. TANGO, A Dosagem IPT - Aplicações, A Construção Em São Paulo, Seção Concreto. (1994).

[8] N. NM248, NBR NM 248: Agregados - Determinação da composição granulométrica, Test. (2003)

[9] NBR NM 67, Concreto - Determinação da consistência pelo abatimento do tronco de cone:, 1998.

[10] ABNT, NBR 16605: Cimento Portland e outros materiais em pó Determinação da massa específica, Assoc. Bras. Normas Técnicas. (2017)

[11] ABNT NBR NM 53, Coarse aggregate - Determination of the bulk specific gravity, apparent specific gravity and water absorption, Brazilian Assoc. Tech. Stand. (2009).

[12] ABNT, NBR 5738: Concreto - Procedimento para moldagem e cura de corpos de prova, Assoc. Bras. Normas Técnicas. (2015). https://doi.org/01.080.10; 13.220.99.

[13] ABNT, Concrete - Compression test of cylindrical specimens ABNT NBR 5739, Brazilian Assoc. Tech. Stand. (2018).

[14] R.C. Dorf, The engineering handbook, second edition, 2004.

[15] ABNT, NBR 7211: Agregados para concreto - Especificação, Assoc. Bras. Normas Técnicas. (2019). https://doi.org/01.080.10; 13.220.99.

[16] A.M. Neville, Properties of Concrete, 4th, 2011.

[17] W.N. Lipscomb, The Chemistry of Portland Cement. By Robert Herman Bogue, J. Phys. Colloid Chem. 52 (1948) 434-434. https://doi.org/10.1021/j150458a021.

[18] ABNT, NBR 8953: Concreto para fins estruturais - Classificação pela massa específica, por grupos de resistência e consistência, Assoc. Bras. Normas Técnicas. (2015). https://doi.org/01.080.10; 13.220.99. 